\title{
THE TUNGUSKA EVENT AS RECORDED IN A TREE TRUNK
}

\section{HITOSHI YONENOBU}

College of Education, Naruto University of Education, Naruto 772 Japan

and

\section{CHISATO TAKENAKA}

\author{
School of Agricultural Sciences, Nagoya University, Nagoya 464-01 Japan
}

\begin{abstract}
A living spruce tree was collected near the explosion center of the Tunguska event that occurred in 1908. We measured annual ring width and studied anatomical features to reconstruct the possible vegetational changes caused by the biological aftereffects of the Tunguska explosion. $\Delta^{14} \mathrm{C}$ of annual rings from 1908 to 1910 was measured with a Tandetron accelerator mass spectrometer. The annual ring width decreased rapidly in 1908-1912, drastically increased in 1913, and decreased gradually thereafter. Traumatic resin ducts were observed in the transition zone between early-and latewood of the annual ring formed in 1908. We thus reconstruct these vegetational changes in the Tunguska forest: the Tunguska explosion damaged forest trees severely for $c a .3 \mathrm{yr}$, releasing rich nutrients from burned plants into the soil, and subsequently the vegetation was stimulated to recover by decreased socio-biological competition and better lighting conditions. $\Delta^{14} \mathrm{C}$ values range from -28.2 to $-1.5 \%$ for Tunguska spruce, and from -29.7 to $12.6 \%$ for Hinoki cypress. These fluctuations are within the ranges presented in Stuiver and Becker (1993), suggesting no evidence of anomalies of cometary origin in carbon isotopic composition. We found no significant difference between $\Delta^{14} \mathrm{C}$ of Tunguska spruce and of Hinoki cypress.
\end{abstract}

\section{INTRODUCTION}

The explosion over Tunguska on 30 June 1908 is the largest such event in recorded history, and is still incompletely understood. The explosion is estimated to have occurred in the area between the Podkamennaya and Nizhnyaya Tunguska Rivers, Siberia $\left(60^{\circ} 55^{\prime} \mathrm{N}, 101^{\circ} 57^{\prime} \mathrm{E}\right)$. Trees were blown down over an area with a radius of $30-40 \mathrm{~km}$; felled trees remain there, burned, bent over or uprooted with their roots pointing toward the center of the explosion in a radial manner due to thermal and blast effects. Since L. A. Kulik's first expedition in 1927, much factual material has been gathered (see, e.g., Cowan, Alturi and Libby 1965), and various theories of causation advanced: antimatter, a small black hole and, inevitably, an exploding flying saucer, have all been proposed as means of liberating tens of megatons of energy in the atmosphere without cratering the Earth's surface (Chyba, Thomas and Zahnle 1993). Vasilyev and Andreev (1984) suggested that if the Tunguska object had a cometary origin, anomalies in isotopic composition can be expected in the vicinity. Lerman, Mook and Vogel (1967) showed that there was no hemispherical increase in the ${ }^{14} \mathrm{C}$ content of tree rings following the event in 1908, and concluded that the antimatter hypothesis of Cowan, Alturi and Libby (1965) was highly unlikely. Although it is an ecologically important issue, the biological aftereffects of the explosion have been the subject of little investigation, apart from Kolesnikov et al. (1996).

Because trees have definite annual rings produced by photosynthetic growth (except in the tropics), we can use them to obtain information on past environment. Numerous tree-ring chronologies of ring widths or carbon isotopes have been developed to give an accurate chronology for calibration of ${ }^{14} \mathrm{C}$ dates (Stuiver and Becker 1993), or as a means of reconstructing past climate (e.g., Hughes et al. 1984; Leavitt and Long 1989). We analyzed a tree trunk sample collected near the Tunguska explosion area to reconstruct the possible vegetational changes in the explosion area by tree-ring analysis. The $\Delta^{14} \mathrm{C}$ of the tree cellulose was also investigated. 


\section{MATERIALS AND METHODS}

\section{Tree Samples}

A cross-sectional disk was cut out of a living tree, located $7.3 \mathrm{~km}$ north-northeast from the explosion center $\left(60^{\circ} 56^{\prime} 16^{\prime \prime} \mathrm{N}, 101^{\circ} 55^{\prime} 45^{\prime \prime} \mathrm{E}\right)$. The sample tree had survived deforestation caused by the explosion. The vegetation of the area is a tundra forest dominated by Picea spp., Pinus spp. and other minor coniferous or broadleaved species. We identified the species of the sample tree as Picea sp. (spruce), possibly Picea schrenkiana Fisch et May or an allied species, by the microscopic observation of xylem, comparing its anatomical characteristics with those given in Greguss (1955). The sample disk had 123 annual rings (ca. $21.7 \mathrm{~cm}$ in diameter) in 1992 and had 39 (ca. $8.3 \mathrm{~cm}$ in diameter) in the year of the explosion. Annual ring widths of the spruce disk were measured from the pith to the outermost ring along four radii as orthogonal as possible, one among them pointing toward the center of the explosion center, with a specially developed tree-ring analysis system. In addition, we used ten tree rings from 1908-1910 out of three samples of Chamaecyparis obtusa Endl. (Hinoki cypress) comprising the master tree ring chronology (Takeda, Sweda and Yonenobu 1992; Yonenobu 1994).

\section{${ }^{14} \mathrm{C}$ Measurement}

Three annual rings formed in AD 1908-1910 were separated with a razor knife to prepare the samples for ${ }^{14} \mathrm{C}$ dating from each of the spruce and cypress samples. Wood samples were sliced with a sliding microtome ( $c a .10 \mu \mathrm{m}$ in thickness) for each of the annual rings, then washed in distilled water with supersonic cleaning for $10 \mathrm{~min}$. This thinly sliced wood section was treated four times with $1.2 \mathrm{~N} \mathrm{NaOH}\left(80^{\circ} \mathrm{C}, 2 \mathrm{~h}\right)$ to eliminate possible contamination by carbonaceous materials. Wood cellulose was isolated according to a slightly modified Wise method (Fengel and Wegener 1983; Aoki et al. 1996). Each sample was combusted to $\mathrm{CO}_{2}$ with $\mathrm{CuO}$ at $900^{\circ} \mathrm{C}$ for $12 \mathrm{~h}$ in a sealed Vycor tube. $\mathrm{CO}_{2}$ was cryogenically purified in a recirculating line. Half the total amount of $\mathrm{CO}_{2}$ was analyzed in an isotope-ratio mass spectrometer (Finnigan MAT ${ }^{\mathrm{TM}}$ 252); the remainder was reduced to graphite on Fe powder at $650^{\circ} \mathrm{C}$ according to Kitagawa et al. (1993). The graphitized samples were analyzed on a Tandetron accelerator mass spectrometer at Nagoya University, Japan (Nakamura et al. 1985). The measured ${ }^{13} \mathrm{C} /{ }^{12} \mathrm{C}$ and ${ }^{14} \mathrm{C} /{ }^{13} \mathrm{C}$ ratios were calculated with respect to the PDB standard.

\section{RESULTS AND DISCUSSION}

\section{Ring Width Variation of Tunguska Spruce}

Figure 1 shows the variation of ring width indices $(R W T)$ of Tunguska spruce. The radius measured was pointing toward the explosion center. $R W I$ was computed with respect to the third-order polynomial fitting in order to remove the general trend in the measured ring width. The time-series variation of $R W I$ and microscopic features of the annual rings show the following three patterns:

1. fluctuation with a 1-2 yr periodicity by 1908 , as often observed in growth of juvenile conifers, with no abnormal evidence in tree growth and anatomical features, except traumatic resin ducts found in the transition zone between early- and latewood of the 1908 ring;

2. extremely low growth rate during 1909-1912 with normal cell formation;

3. rapid increase of growth in 1913, and subsequently, gradual decrease with compression wood during 1913-1915. 


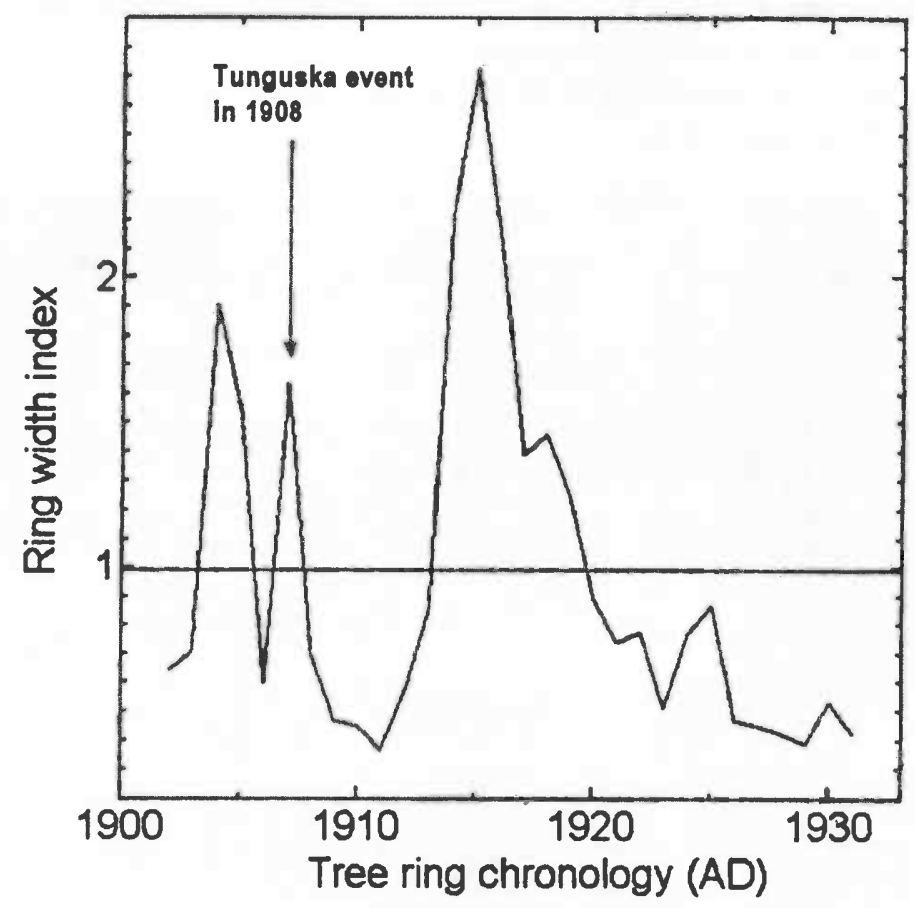

Fig. 1. Ring-width indices of Tunguska spruce

Figure 2 shows the SEM photographs of the transverse section of Tunguska spruce for the annual rings of 1908-1909. The presence of traumatic resin ducts in 1908, a type of cells produced by damage to leaves and roots, is obviously due to the blast and thermal effects of the explosion. The consequent decrease in vital photosynthetic organs contributed to the extremely low growth in 19091912. The compression wood in 1913-1915, toward the explosion center, was produced by water deficits in the deforested, open vegetation. These results can be interpreted to reconstruct the threestage history of vegetational change given in Table 1.

TABLE 1. Reconstructed Vegetational Change in Tunguska Spruce

\begin{tabular}{ll}
\hline Period & Vegetational change \\
\hline Through 1907 & $\begin{array}{l}\text { A typical coniferous forest grew normally in the subarctic region. } \\
\text { Tunguska event deforested the area. The socio-biological competition } \\
\text { was moderated. Inorganic nutrients contained in plants were released } \\
\text { back to the soil from burned plants. }\end{array}$ \\
$\begin{array}{l}\text { Vegetation growth was depressed by damage. } \\
\text { ca. } 1913 \text { and } 1912 \\
\text { later }\end{array}$ & $\begin{array}{l}\text { Trees recovered their photosynthetic organs. Soil rich in nutrients and } \\
\text { good light environment stimulated vegetation growth to form the cur- } \\
\text { rent ecosystem. }\end{array}$ \\
\hline
\end{tabular}

\section{$\Delta^{14} \mathrm{C}$ Variation During 1908-1910}

Table 2 shows the experimental results; $\Delta{ }^{14} \mathrm{C}$ is also presented in Figure 3 . The $\Delta^{14} \mathrm{C}$ values range from -28.2 to $-1.5 \%$ for Tunguska spruce, and from -29.7 to $12.6 \%$ for Hinoki cypress. Their fluctuations are within those presented in Stuiver and Becker (1993). Comparing the $\Delta^{14} \mathrm{C}$ values of Tunguska spruce with those of Hinoki cypress, no statistical difference was detected by Student's t- 
test $(t=0.35)$. Vasilyev and Andreev (1984) noted that if the Tunguska object had a cometary origin, the anomalies in the isotopic composition can be expected. However, our results indicate that no evidence of icy fragments of a comet nucleus is detectable, considering the variation of atmospheric ${ }^{14} \mathrm{C}$ and the error of measurement.

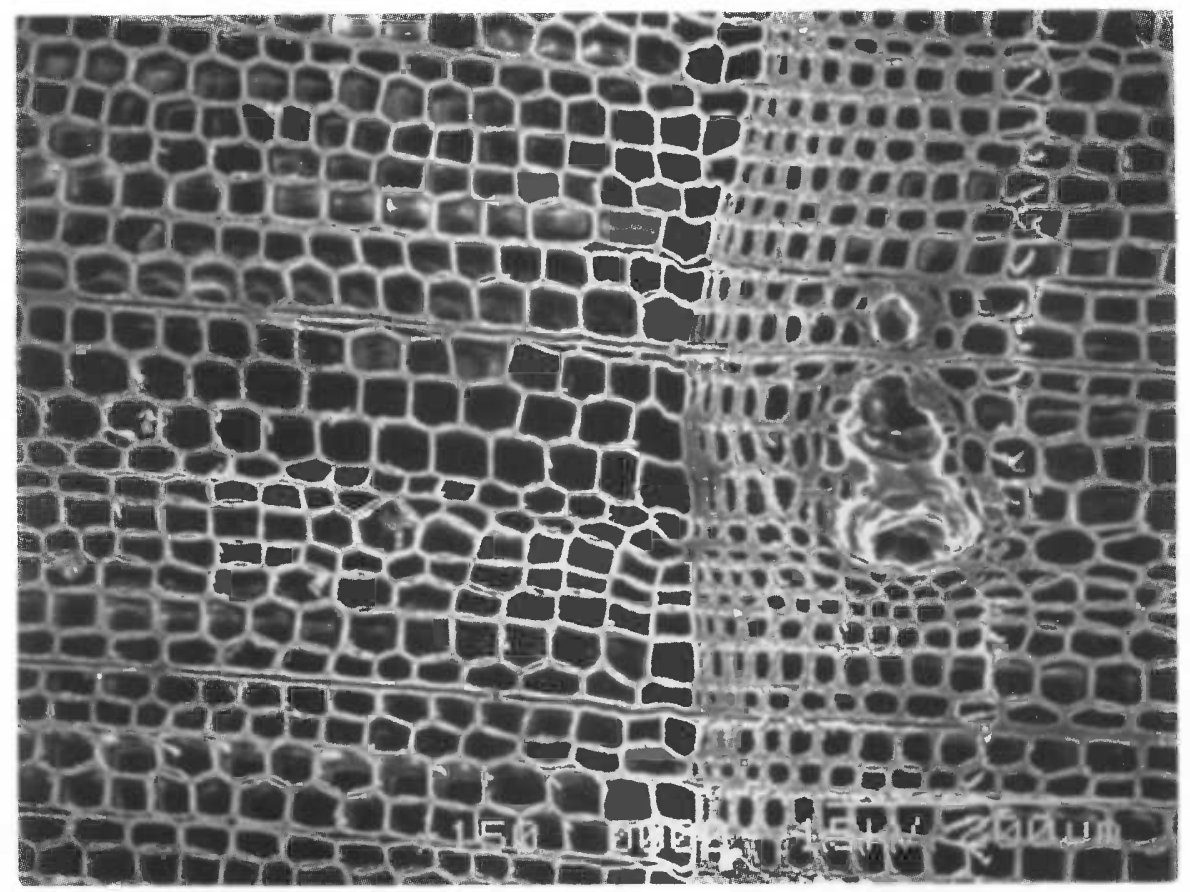

Fig. 2. SEM photograph of the transverse section of Tunguska spruce for the annual rings of 1908-1909

TABLE 2. Results of Isotopic Measurements on Tunguska-Area Trees

\begin{tabular}{lcccc}
\hline Sample & $\begin{array}{c}\text { Year } \\
(\mathrm{AD})\end{array}$ & $\begin{array}{c}\delta^{14} \mathrm{C} \\
(\%)\end{array}$ & $\begin{array}{c}\delta^{13} \mathrm{C} \\
(\% 0)\end{array}$ & $\begin{array}{c}\Delta^{14} \mathrm{C} \\
(\% 0)\end{array}$ \\
\hline Tunguska spruce & 1908 & $-16.5 \pm 18.9$ & $-19.06 \pm 006$ & $-28.2 \pm 18.6$ \\
& 1909 & $7.7 \pm 5.8$ & $-20.44 \pm 0.06$ & $-1.5 \pm 5.8$ \\
& 1910 & $-8.8 \pm 3.6$ & $-21.62 \pm 0.06$ & $-15.5 \pm 3.6$ \\
Hinoki cypress \#1 & 1908 & $6.6 \pm 14.4$ & $-21.26 \pm 0.06$ & $-0.9 \pm 14.3$ \\
& 1909 & $-18.8 \pm 11.9$ & $-21.41 \pm 0.06$ & $-25.8 \pm 11.8$ \\
& 1910 & $-4.6 \pm 7.1$ & $-20.19 \pm 0.06$ & $-14.2 \pm 7.1$ \\
Hinoki cypress \#2 & 1908 & $-210 \pm 19.2$ & $-20.56 \pm 0.06$ & $-29.7 \pm 19.0$ \\
& 1909 & $21.3 \pm 9.7$ & $-20.72 \pm 0.06$ & $12.6 \pm 9.6$ \\
& 1910 & $20.5 \pm 14.7$ & $-19.79 \pm 0.06$ & $9.9 \pm 14.6$ \\
Hinoki cypress \#3 & 1909 & $-8.3 \pm 9.6$ & $-21.48 \pm 0.06$ & $-15.3 \pm 9.5$ \\
\hline
\end{tabular}




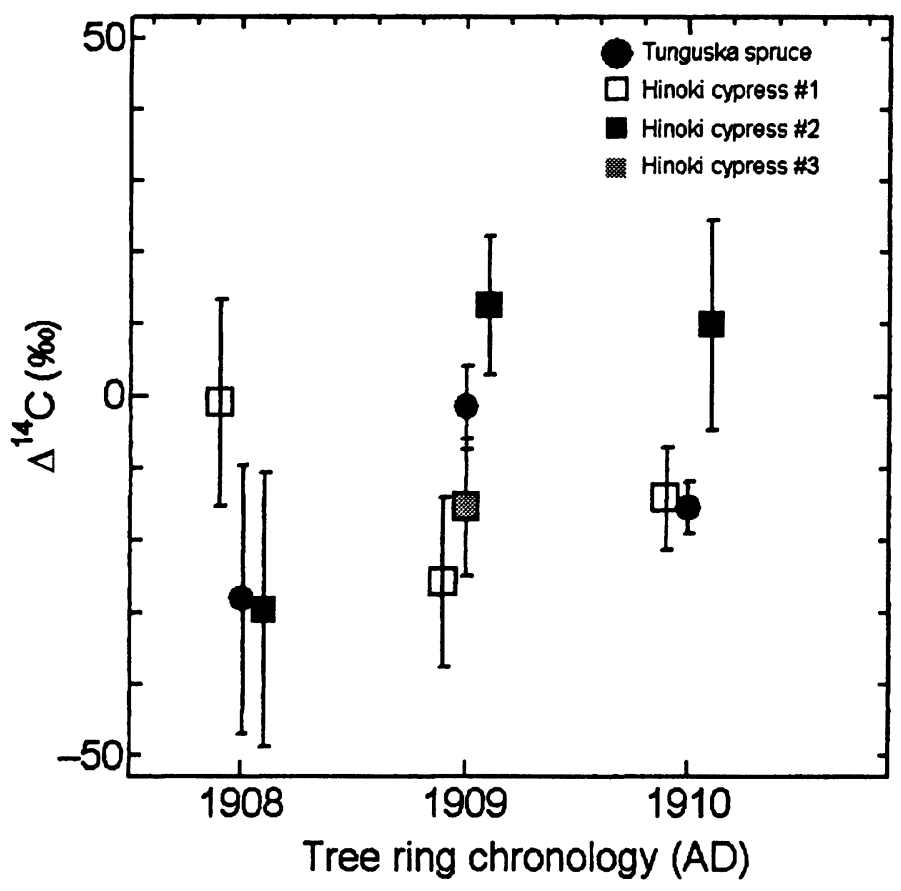

Fig. 3. $\Delta^{14} \mathrm{C}$ variation in Tunguska spruce and Hinoki cypress, 19081910

\section{REFERENCES}

Aoki, H., Yonenobu, H., Ikeda, A., Nakamura, T. and Wada, H. 1996 Possible estimation of global biomass from carbon isotopic fluctuation of atmospheric carbon dioxide using tree rings of Chamaecyparis obtusa Endl. Summaries of Researches Using AMS at Nagoya University 7: 284-299.

Chyba, C. F., Thomas, P. J. and Zahnle, K. J. 1993 The 1908 Tunguska explosion: Atmospheric disruption of a stony asteroid. Nature 361(7): 40-44.

Cowan, C. D., Alturi, C. R. and Libby, W. F. 1965 Possible anti-matter content of the Tunguska meteor of 1908. Nature 4987: 861-865.

Greguss, P. 1955 Identification of Living Gymnosperms on the Basis of Xylotomy. Budapest, Akademiai Kiado: 263 p.

Fengel, D. and Wegener, G. 1983 Wood: Chemistry, Ultrastructure, Reactions. Berlin, Walter de Gruyter \& Co.: 613 p.

Hughes, M. K., Schweingruber, F. H., Cartwright, D. and Kelly, P. M 1984 July-August temperature at Edinburgh between 1721 and 1975 from tree ring density and width data. Nature 308: 341-344.

Kitagawa, H., Masuzawa, T., Nakamura, T. and Matsumoto, E. 1993 A batch preparation method for graphite targets with low backgrounds for AMS ${ }^{14} \mathrm{C}$ measurements. Radiocarbon 35(2): 295-300.

Kolesnikov, E. M., Boettger, T., Hiller, A., Junge, F. W. and Kolesnikova, N. V. 1996 Isotope anomalies of carbon, hydrogen and nitrogen in peat from the area of the
Tunguska cosmic body explosion (1908). Isotopes in Environmental and Health Studies 32: 347-361.

Leavitt, S. W. and Long, A. 1989 The atmospheric $\delta^{13} \mathrm{C}$ record as derived from 56 pinyon trees at 14 sites in the southwestern United States. In Long, A., Kra, R. S. and Srdoc, D., eds., Proceedings of the 13th International ${ }^{14} \mathrm{C}$ Conference. Radiocarbon 31(3): 469-474.

Lerman, J. C., Mook, W. G. and Vogel, J. C. 1967 Effect of Tunguska meteor and sunspots on radiocarbon in tree rings. Nature 216: 990-991.

Nakamura, T., Nakai, N., Sakase., T., Kimura, M., Ohishi, S., Taniguchi, M. and Yoshioka, S. 1985 Direct detection of radiocarbon using accelerator techniques and its application to age measurement. Japanese Journal of Applied Physics 24: 1716-1723.

Stuiver, M. and Becker, B. 1993 High-precision decadal calibration of the radiocarbon time scale, AD 1950 6000 BC. In Stuiver, M., Long, A. and Kra, R. S., eds., Calibration 1993. Radiocarbon 35(1): 35-66.

Takeda, S., Sweda, T. and Yonenobu, H. 1992 Improvement and extension of existing dendrochronology by straddled logs back to 12 th century. Tree Rings 5: 1826.

Vasilyev, N. V. and Andreev, G. V. 1989 On the necessity of international investigation into 1908 Tunguska event. The Journal of the IMO 17(4): 122-127.

Yonenobu, H. (ms.) 1994 Radiocarbon concentrations in tree stems. Ph.D. dissertation, Nagoya University: 109 p. 